\title{
Formulation and Evaluation of Eszopiclone Film Coated Immediate Release Tablets by Direct Compression Method
}

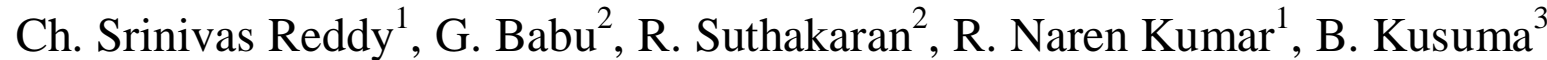 \\ ${ }^{1}$ Pharmaceutics, ${ }^{2}$ Pharmaceutical Chemistry, ${ }^{3}$ Pharmacognosy
}

\begin{abstract}
Eszopiclone is a class of drug with hypnotic effect and mainly used in the treatment of Insomnia. The main objective of the present study was to develop a pharmaceutically equivalent, stable, cost effective and quality improved formulation of immediate release tablets of Eszopiclone using different concentration of disintegrants and diluents mainly MCC. Pre formulation studies were performed prior to formulation. The tablets were compressed using lactose monohydrate, microcrystalline cellulose, colloidal silicon dioxide, croscarmellose sodium, anhydrous dibasic calcium phosphate, magnesium stearate and opadry blue (white for $2 \mathrm{mg}$ ) was used for coating the tablets. The tablets were formulated by direct compression method. And prior to the formulation, the pre formulation parameters analysed are bulk density, tapped density, compressibility index, Hausner's ratio, angle of repose and post compression characteristics like thickness, hardness, friability, disintegration time, drug release and assay. The stability studies were carried out for the reproducible batch F010 (3mg), F009 (1mg) and F010 (2mg) for three months. The results of the present study showed that among all the formulations, F008 for 3mg, F009 for $1 \mathrm{mg}$ and F010 for $2 \mathrm{mg}$ was better in all terms of pre formulation and post compression parameters and showed comparably a good dissolution profile like that of the marketed product, LUNESTA ${ }^{\circledR}$.
\end{abstract}

Keywords: Eszopiclone, Insomnia, Lunesta, depression, hypnotic, sleep onset, non-benzodiazepine, Zopiclone, cyclopyrrolones.

\section{Immediate release drug delivery systems}

The term "immediate release" $11-18 *$ pharmaceutical formulation includes any formulation in which the rate of release of drug from the formulation and/or the absorption of drug, is neither appreciably, nor intentionally, retarded by galenic manipulations. In the present case, immediate release may be provided for by way of an appropriate pharmaceutically acceptable diluent or carrier, which diluents or carrier does not prolong, to an appreciable extent, the rate of drug release and/or absorption. Thus, the term excludes formulations which are adapted to provide for "modified", "controlled", "sustained", "prolonged", "extended" or "delayed" release of drug.

Conventional Technique used in the Preparation of Immediate Release Tablets

1 Tablet molding technique

2 Direct compression technique

3 Granulation technique

4 Mass extrusion technique

\section{Direct Compression Method}

The term "direct compression" is defined as the process by which tablets are compressed directly from powder mixture of API and suitable excipients. No pretreatment of the powder blend by wet or dry granulation procedure is required. Amongst the techniques used to prepare tablets, direct compression is the most advanced technology. It involves only blending and compression, thus offering advantage particularly in terms of speedy production, as it requires fewer unit operations, less machinery, reduced number of personnel and considerably less processing time along with increased product stability.

Direct compression vehicles can be used which are having good flow and compressible characteristics. Commonly used directly compression diluents are: MCC (Microcrystalline cellulose, Spray dried lactose, Starch, Sugar (Sugartab, Nutab), Dicalcium phosphate dihydrate (Di-Tab), Mannitol for chewable tablet.

\section{Advantages}

a. Direct compression is more efficient and economical process as compared to other processes, because it involves only dry blending and compaction of API and necessary excipients.

b. The most important advantage of direct compression is that it is an economical process. Reduced processing times, reduced labor costs, fewer manufacturing steps and less number of equipments are required, less process validation, reduced consumption of power. 
c. Elimination of heat and moisture, thus increasing not only the stability but also the suitability of the process for thermolabile and moisture sensitive API.

d. Particle size uniformity.

e. Prime particle dissolution.

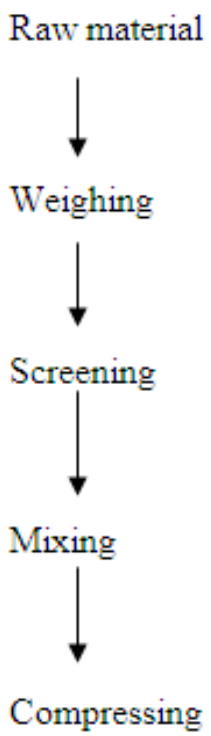

Direct compression process of Tablet

Fig.No.1

\section{Drug profile}

\section{Eszopiclone(Generic name), Lunesta ${ }^{\circledR}$ (Brand name)}

Eszopiclone is a nonbenzodiazepine hypnotic agent that is a pyrrolopyrazine derivative of the cyclopyrrolone class. The chemical name of Eszopiclone is (+)-(5S)-6-(5- chloropyridin-2-yl)-7-oxo-6,7dihydro-5H-pyrrolo[3,4-b] pyrazin-5-yl 4- methylpiperazine-1-carboxylate. Its molecular weight is 388.81, and its empirical formula is $\mathrm{C} 17 \mathrm{H} 17 \mathrm{ClN} 6 \mathrm{O} 3$. Eszopiclone has a single chiral center with an (S)-configuration. It has the following chemical structure:

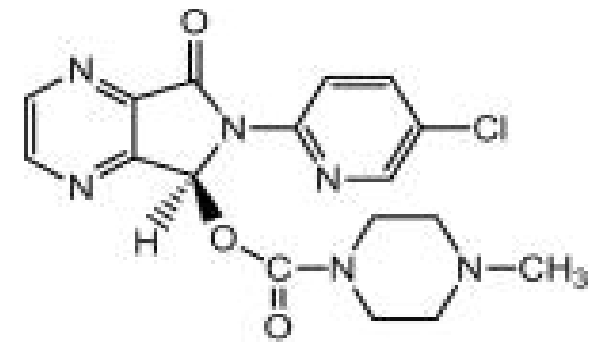

Fig.No.2 Chemical structure of Eszopiclone

\section{a. Pre formulation Studies}

\section{Materials and Methods}

Pre formulation study is an investigation of physical and chemical properties of a drug substance alone and when combined with excipients. It is the first step in the rationale development of dosage form.

\section{Estimation of $\lambda_{\max \text { of }}$ Eszopiclone}

Estimation of $\lambda_{\max }$ of Eszopiclone by Ultraviolet absorption spectrophotometry method based on the measurement of absorbance at spectral range of 200 to $380 \mathrm{~nm}$ of U.V. region.

Medium: methanol

\section{Preparation of solution}

Weigh accurately about $25.0 \mathrm{mg}$ of Eszopiclone standard, in a $50 \mathrm{ml}$ volumetric flask add $40 \mathrm{ml}$ of methanol dissolve and dilute to the volume with Methanol and take $1 \mathrm{ml}$ of above solution in $100 \mathrm{ml}$ volumetric flask and dilute to the volume with methanol. 
Formulation and Evaluation of Eszopiclone Film Coated Immediate Release Tablets by ....

\section{Calibration Curve for the Estimation of Eszopiclone}

Spectrophotometric method based on the measurement of absorbance at $305 \mathrm{~nm}$ of U.V. region was used in the study for estimation of Eszopiclone.

\begin{tabular}{|c|c|}
\hline \% Compressibility & Flow Description \\
\hline $5-15$ & Excellent \\
\hline $12-16$ & Good \\
\hline $18-21$ & Fair \\
\hline $23-28$ & Possible \\
\hline $28-35$ & Poor \\
\hline $35-38$ & Very Poor \\
\hline$>40$ & Extremely Poor \\
\hline
\end{tabular}

Table.No.1 Compressibility Index range

\begin{tabular}{|c|c|}
\hline Hausner's ratio & Flow Character \\
\hline $1.00-1.11$ & Excellent \\
\hline $1.12-1.18$ & Good \\
\hline $1.19-1.25$ & Fair \\
\hline $1.26-1.34$ & Possible \\
\hline $1.35-1.45$ & Poor \\
\hline $1.46-1.59$ & Very Poor \\
\hline$>1.60$ & Very, Very Poor \\
\hline
\end{tabular}

Table No.2 Hausner's ratio range

\section{Angle of Repose(Flow Property)}

Angle of Repose $(\theta)$ is the maximum angle between the surface of a pile of powder and horizontal plane. It is usually determined by Fixed Funnel Method and is the measure of the flowability of powder/granules.

$$
\theta=\tan ^{-1}(\mathbf{h} / \mathbf{r})
$$

Where, $\mathrm{h}=$ height of heap of pile and $\mathrm{r}=$ radius of base of pile

\begin{tabular}{|c|c|}
\hline Angle of repose & Type of flow \\
\hline$<25$ & Excellent \\
\hline $25-30$ & Good \\
\hline $30-40$ & Passable \\
\hline$>40$ & Very Poor \\
\hline
\end{tabular}

Table No.3 Angle of repose range

\section{Stability Studies}

The stability of pharmaceutical ingredients and the products containing them depends on two major factors:

a) The chemical and physical properties of the materials concerned (including the excipients and container closure systems used for packaging of formulated products).

b) Environmental factors, such as temperature, humidity and light and their effect on the drug products.

Frequently, the goal of a pharmaceutical company is to develop a globally acceptable registration stability protocol. A sound stability protocol not only eliminates unnecessary testing but also reduces manufacturing needs, cost and time. This is especially important in current scenario due to increase in the number of possible storage conditions and checkpoints because of stringent regional requirements.

Generally, a finished product should be evaluated under storage conditions that test its thermal stability and if necessary its sensitivity to moisture and potential for solvent loss.

The table below gives the information about the types of stability studies on which the drug is to be loaded.

\begin{tabular}{|c|c|c|}
\hline Study & Storage condition & Minimum time period \\
\hline \multirow{2}{*}{ Long } & $25^{\circ} \mathrm{C} \pm 2^{\circ} \mathrm{C} / 60 \% \mathrm{RH} \pm 5 \% \mathrm{RH}$ & 6 months \\
& $30^{\circ} \mathrm{C} \pm 2{ }^{\circ} \mathrm{C} / 65 \% \mathrm{RH} \pm 5 \% \mathrm{RH}$ & 6 months \\
\hline Intermediate & $30^{\circ} \mathrm{C} \pm 2{ }^{\circ} \mathrm{C} / 65 \% \mathrm{RH} \pm 5 \% \mathrm{RH}$ & months \\
\hline Accelerated & $40^{\circ} \mathrm{C} \pm 2{ }^{\circ} \mathrm{C} / 75 \% \mathrm{RH} \pm 5 \% \mathrm{RH}$ & \\
\hline
\end{tabular}

Table No.4 Types of stability studies based on storage conditions

In the present study the finished products are loaded for accelerated stability studies. 
Stability studies were conducted for the film coated formulations at $40^{\circ} \mathrm{c} \pm 2^{\circ} \mathrm{C} / 75 \% \mathrm{RH} \pm 5 \% \mathrm{RH}$ for about 3 months in stability chamber (Thermo lab). Samples were analyzed for assay, dissolution and water by kf.

\section{Results and Discussions}

A.Pre-formulation results Calibration curve of Eszopiclone

\begin{tabular}{|c|c|c|}
\hline Sl. No & Concentration & Absorbance \\
\hline 1 & 4 & 0.139 \\
\hline 2 & 8 & 0.278 \\
\hline 3 & 12 & 0.408 \\
\hline 4 & 16 & 0.542 \\
\hline 5 & 20 & 0.671 \\
\hline 6 & 24 & 0.798 \\
\hline
\end{tabular}

Table no.5 Calibration curve

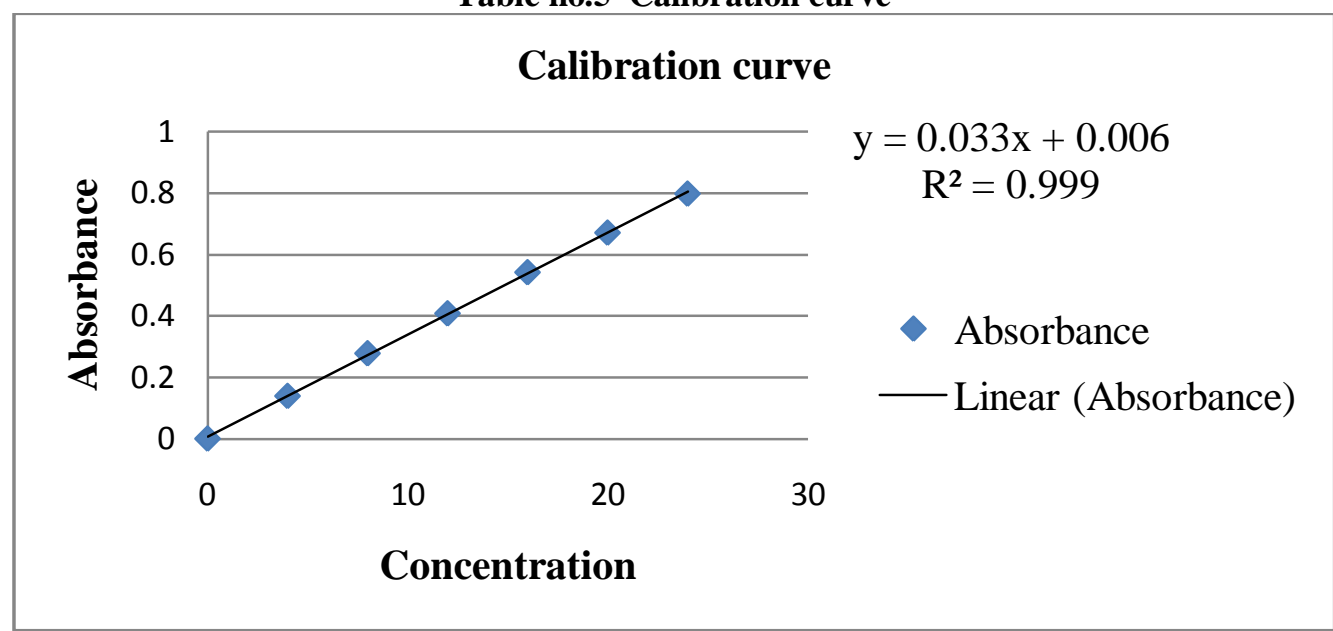

Slope $\quad: 0.0335$

Intercept $\quad: 0.0064$

Correlation coefficient $\quad: 0.9997$

Evaluation of Powder Blend

\begin{tabular}{|c|c|c|}
\hline Sl.No & Hausner's ratio & Angle of repose $\mathbf{(}^{\mathbf{}}$ ) \\
\hline 1 & 1.187 & 34.25 \\
\hline 2 & 1.227 & 32.36 \\
\hline 3 & 1.184 & 31.45 \\
\hline 4 & 1.204 & 30.39 \\
\hline 5 & 1.207 & 28.73 \\
\hline 6 & 1.191 & 29.58 \\
\hline 7 & 1.197 & 32.57 \\
\hline 8 & 1.206 & 31.45 \\
\hline 9 & 1.198 & 32.34 \\
\hline 10 & 1.205 & 31.87 \\
\hline
\end{tabular}

Table No.6 Evaluation of powder blend

\section{Pre formulation studies}

From the above data we can conclude that the Eszopiclone complies with all the specifications mentioned above. Eszopiclone is white in colour and soluble in $0.1 \mathrm{~N} \mathrm{HCl}$, weakly soluble acetate and phosphate buffer mediums. From physico mechanical characterization we found that Eszopiclone has a good flow properties which plays an important role in the selection of tablet manufacturing process and since, the flow properties are good and as the market product has used the direct compression method in the manufacture of tablet, we also use the same process in the manufacture of Eszopiclone film coated tablets. By compatibility studies it is clear that there is no interaction between the drug and excipients. And even between the excipients. 
Formulation and Evaluation of Eszopiclone Film Coated Immediate Release Tablets by ....

Compression parameters

\begin{tabular}{|c|c|c|c|c|c|c|}
\hline $\begin{array}{c}\text { Formulation } \\
\text { Trail }\end{array}$ & $\begin{array}{c}\text { Diameter } \\
(\mathbf{m m})\end{array}$ & $\begin{array}{c}\text { Thickness } \\
(\mathbf{m m})\end{array}$ & $\begin{array}{c}\text { Hardness } \\
(\mathbf{k p})\end{array}$ & Disint.time & $\begin{array}{c}\text { Friability } \\
(\%)\end{array}$ & $\begin{array}{c}\text { Coated tablet } \\
\text { (avg. } 10 \text { tablets) }\end{array}$ \\
\hline F001 & 6.45 & 3.21 & 7.4 & $1.55 \mathrm{~min}$ & 0.6 & 103.21 \\
\hline F003 & 6.45 & 3.21 & 6.8 & $1.24 \mathrm{~min}$ & 0.6 & 103.74 \\
\hline F004 & 6.45 & 3.19 & 7.3 & $1.02 \mathrm{~min}$ & 0.7 & 103.97 \\
\hline F005 & 6.45 & 3.18 & 7.3 & $1.01 \mathrm{~min}$ & 0.5 & 103.79 \\
\hline F008 & 6.45 & 3.19 & 7.4 & $52 \mathrm{sec}$ & 0.6 & 103.89 \\
\hline \multicolumn{7}{|c|}{ For 1mg tablets } \\
\hline F009 & 6.1 & 3.18 & 7.1 & $50 \mathrm{sec}$ & 0.6 & 103.34 \\
\hline \multicolumn{7}{|c|}{ For $2 \mathrm{mg}$ tablets } \\
\hline F010 & 6.1 & 3.12 & 6.9 & $53 \mathrm{sec}$ & 0.7 & 103.93 \\
\hline
\end{tabular}

Table No.7 Compression parameters

\section{Summary and Conclusion} drug delivery.

The study was undertaken with the aim to develop a stable form of Eszopiclone by Immediate release

The API, Eszopiclone was selected and formulated as immediate release film coating tablets of 3, 2 and $1 \mathrm{mg}$ and their dissolution profiles were compared with the dissolution profile of market products product i.e., LUNESTA ${ }^{\circledR}$.

In the present work pre-formulations were conducted to know the drug excipient compatibility and to generate information useful to the formulation development for a stable and bioavailable dosage forms. Based on the results suitable excipients were selected for formulation development. During pre-formulation the parameters bulk density, tapped density, Carr's index and Hasner's ratio, angle of repose, particle size analysis and solubility.

Tablets were prepared by direct compression technique. During development of formula various inprocess tests such as weight variation, hardness, thickness and disintegration time were evaluated. Core tablets were coated with coating suspension to $12 \%$. Finished products were evaluated for dissolution, water content and assay. The developed trails were tested for invitro dissolution profile and compared with the reference product LUNESTA ${ }^{\circledR}$. The invitro dissolution profile of formula 8 for $3 \mathrm{mg}$ (formula 9 for $2 \mathrm{mg}$ and formula 9 for $1 \mathrm{mg}$ ) was similar to that of reference product, LUNESTA ${ }^{\circledR}$.

The optimised batch tablets were packed in HDPE (High Density Poly Ethylene) containers and performed stability studies at $40^{\circ} \mathrm{C} / 75 \% \mathrm{RH}$. Stability studies were evaluated initially, 30 days and 60 days. The results were compared with the predetermined specifications. All the results were found to be satisfactory. Hence the developed formula was stable.

The objective of the present project was successfully achieved by developing the product, giving the same release profile to that of market products product, LUNESTA ${ }^{\circledR}$

\section{Acknowledgement}

Milestones in life are achieved, not by individual efforts but by blessings and guidance of elders, near and dear ones. I therefore take this opportunity to express my acknowledgements to all of them.

I am thankful to almighty Shree Laxmi Narasimha Swamy for giving me life and my parents and brother for educating me and keeping my requirements in priority at all situations. Without their unconditional support and encouragement it would have been impossible to pursue my interest.

\section{References}

[1]. $\quad$ Chein YW. Novel drug delivery systems. New York .marcel dekker. Inc., $2^{\text {nd }} e d^{\text {n }} ; 1992 ; 50: 139-140$

[2]. Indurwade NH, Rajyaguru TH, Nakhat PD. Novel Approach - Fast DissolvingTablets, Indian Drugs 2002;39(8):405-9

[3]. Sahoo S, Mishra B, Biswal PK. Fast Dissolving Tablet: As A Potential Drug Delivery System. Drug Invention Today 2010;2(2):130133.

[4]. Ratnaparkhi PM, Dr.Mohanta GP, Dr. Upadhyay L. Review On: Fast Dissolving Tablet.Journal of Pharmacy Research. January 2009;2(1):5-12.

[5]. Gupta A, Mishra AK, Gupta V. Recent Trends of Fast Dissolving Tablet - An Overview of Formulation Technology. International Journal of Pharmaceutical \& Biological Archives 2010;1(1):1-10.

[6]. Reddy L. H., Ghose B. and Rajneesh, Indian J. Pharm. Sci., 2002;64(4): 331-36.

[7]. Biradar SS, Bhagavati ST, Kuppasad IJ. Fast Dissolving Drug Delivery Systems: A Brief Overview. The Internet Journal of Pharmacology 2006: 4(2).

[8]. Prajapati BG, Ratnakar N. A Review on Recent patents on Fast Dissolving Drug Delivery System.International Journal of PharmTech Research.JulySept 2009;1(3):790-98.

[9]. Wagh MA, Kothawade DP. Techniques used in orally disintegrating drug delivery system. International Journal of Drug Delivery 
2- 2010:98-107.

[10]. Ahmed IS, Nafadi MM, Fatahalla FA. Formulation of fast-dissolving ketoprofen tablet using freeze-drying in blisters technique. Drug Dev.Ind. Pharm 2006;32:437-42.

[11]. Koizumi K, Watanabe Y. New method of preparing high-porosity rapidly saliva soluble compressed tablets using mannitol with camphor, a subliming material. International Journal of Pharmaceutics 152 (1997):127-31.

[12]. Shukla D, Chakraborty S. Mouth dissolving tablets. An overview of formulation technology. Sci. pharm. 2009;76:309-26.

[13]. Ringard J, Guyot-Hermann AM. Calculation of disintegrant critical concentration in order to optimize tablets disintegration. Drug DevInd Pharm. 1988;14:2321-39.

[14]. Debjit B, Chiranjib. B, Yadav J, Chanidra RM. Emerging Trends of disintegrants used in Formulation of Solid Dosage Form. Scholars Research Library. Der Pharmacia Lettre, 2010;2(1):495-504

[15]. Sammour OA, Hammad MA, Megrab NA. Formulation And Optimization Of Mouth Dissolve Tablets Containing Rofecoxib Solid Dispersion. AAPS PharmSciTech. 2006;7(2):162-69.

[16]. Gulati S. Childhood Hypertension-Review Article. IndianPediatrics. April2006;43: 326-33.

[17]. Sorof, JM, Lai, D, Turner, J, Poffenbarger T, Portman PJ. Overweight, ethnicity and the prevalence of hypertension in school-aged children.Pediatrics 2004;113:475-82

[18]. The sixth report of the Joint National Committee on Detection, Evaluation and Treatment of High Blood Pressure. JNC-VI, Arch. Intern Med,157,1997:2413-46.

[19]. Seth, S.D;'T.B. of Pharmacology'. "Drug acting on cardiovascular system", B.I Churchill Livingstone Pvt .ltd, $2^{\text {nd }}$ ed ${ }^{\text {n }} .199-353$

[20]. Katzung BG. Basic and Clinical Pharmacology.Ninth edition, New Delhi. 2004:160.

[21]. The seventh report of the Joint National Committee on Detection, Evaluation and Treatment of High Blood Pressure. JNC-7. NIH PublicationNo:03 -5233, December 2003. 